\title{
Replacement of the retractable roof at the Bad Hersfeld monastery
}

\author{
Werner Fröhlich
}

Velabran GmbH, membrane roffs and consulting

Florastraße 26b; 81827 München

Tel.: 0043-89-45665151

e-mail: office@velabran.com

web page: www.velabran.com

\begin{abstract}
In 775 a.C. Charlemagne raised the Hersfeld monastery to an imperial abbey, built till 850 a.C.

To use the space at the abbey for annual festivals between 1958 - 1967 Frei Otto, a pioneer in tensile lightweight architecture, designed a retractable membrane roof. In 1968 the fabrication and installation of the $1600 \mathrm{~m}^{2}$ retractable membrane roof has been completed with a grand-opening. The PVC/PES membrane roof is suspended by 14 motorized cable clamps spanned over a $36 \mathrm{~m}$ higher mas to external tie-back points avoiding any contact with the existing historical building.
\end{abstract}

In 2019 the complete membrane roof surface has been replaced. For this replacement the initial design has been evaluated and optimized. The complete site works for the replacement took 6 weeks. The presentation will describe the relevant design, optimisation and installation works that took place as part of the replacement.

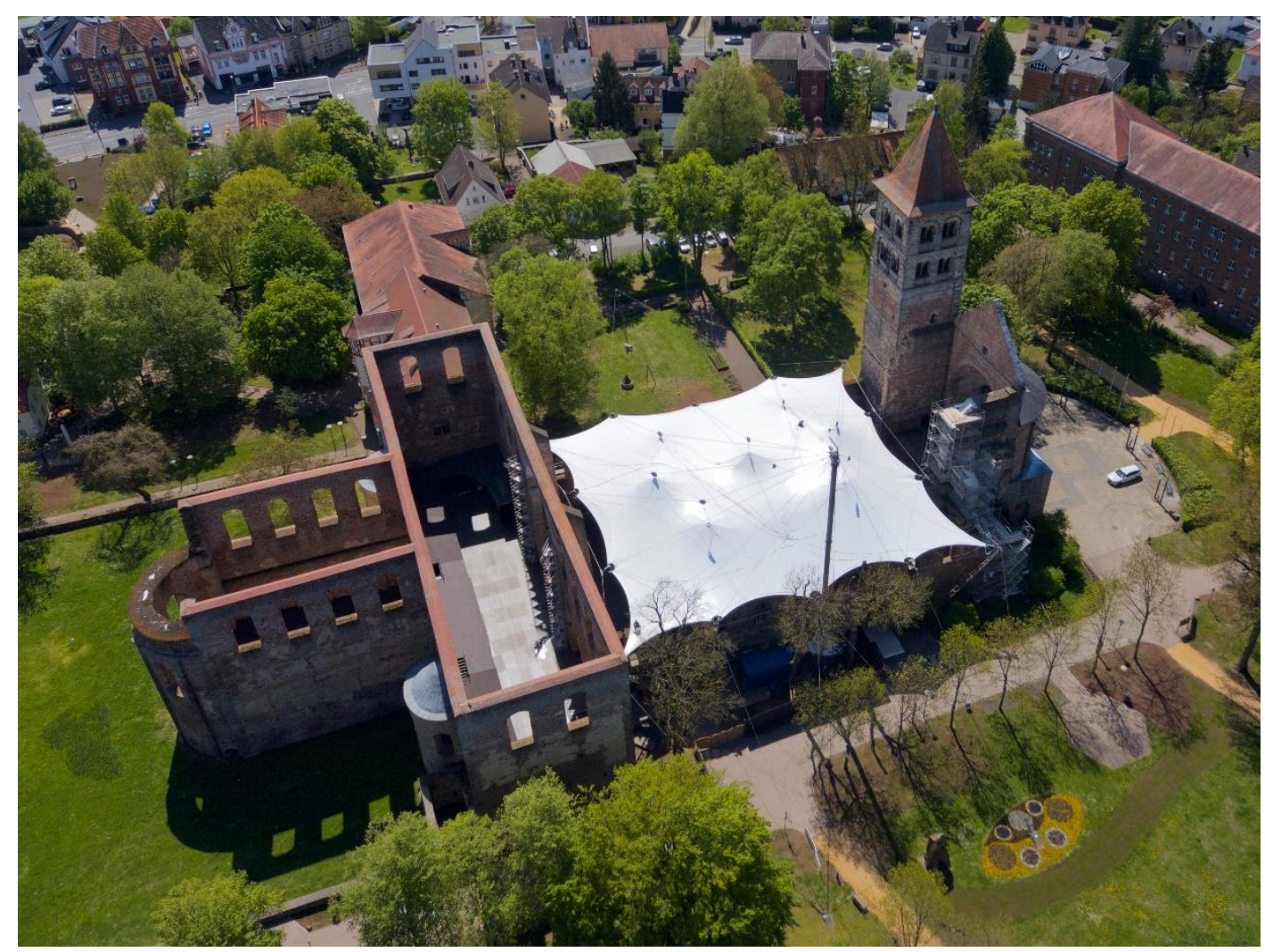

